\title{
Natural Antioxidants: Function and Sources
}

\author{
Yevgenia Shebis $^{1}$, David Iluz ${ }^{1,2}$, Yael Kinel-Tahan ${ }^{1 *}, Z_{v y}$ Dubinsky $^{1}$, Yaron Yehoshua ${ }^{1}$ \\ ${ }^{1}$ The Mina \& Everard Goodman Faculty of Life Sciences, Bar-Ilan University, Ramat-Gan, Israel; ${ }^{2}$ Department of Environmental \\ Science and Agriculture, Beit Berl College, Kfar Saba, Israel. \\ Email: *yaelkinel@gmail.com
}

Received April 10"th, 2013 ; revised May 12 $2^{\text {th }}, 2013$; accepted May 20 ${ }^{\text {th }}, 2013$

Copyright (C) 2013 Yevgenia Shebis et al. This is an open access article distributed under the Creative Commons Attribution License, which permits unrestricted use, distribution, and reproduction in any medium, provided the original work is properly cited.

\begin{abstract}
The definition of antioxidants, given in 1995 by Halliwell and Gutteridge, stated that an antioxidant is "any substance that, when present at low concentrations compared with that of an oxidizable substrate, significantly delays or inhibits oxidation of that substrate" [1]. In 2007, Halliwell gave a more specific definition, stating that an antioxidant is "any substance that delays, prevents or removes oxidative damage to a target molecule” [2]. Oxidation reactions produce free radicals that can start multiple chain reactions that eventually cause damage or death to the cell. Antioxidants remove these free-radical intermediates by being oxidized themselves, and inhibit other oxidation reactions, thus stopping the harmful chain reactions. Such oxidative processes are dangerous for all living cells, especially those in proximity to sites where active oxygen is released by photosynthesis. Spontaneous oxidation causes food rancidity and spoilage of medicines. Furthermore, oxidative stress is an important part of many human diseases that can occur, inter alia, due to a lack of appropriate nutrition and exercise, air pollution, smoking, and more, leading to lethal diseases, such as cancer. Therefore, it is imperative to include antioxidants in our diets. Due to the fact that synthetically produced antioxidants are currently used in the food and pharmaceutical industries in order to prolong product shelf life, there is currently a strong trend to search for large, available, and efficient natural sources of antioxidants to replace the synthetic ones, thus minimizing damage to our cells.
\end{abstract}

Keywords: Algae; Antioxidant; Disease

\section{Introduction}

\subsection{Antioxidant Cell Functions}

There are two major groups of antioxidants in living cells: enzymatic antioxidants and non-enzymatic antioxidants. These groups are divided into several subgroups. The enzymatic antioxidants are divided into primary and secondary enzymatic defenses [3]. The primary defense is composed of three important enzymes that prevent the formation of and neutralize free radicals: glutathione peroxidase, which donates two electrons to reduce peroxides by forming selenols and also eliminates peroxides as potential substrates for the Fenton reaction; catalase, which turns hydrogen peroxide into water and molecular oxygen-one of the most important and efficient antioxidants known today, when just one molecule of catalase converts 6 billion molecules of hydrogen peroxide [4]; and lastly, superoxide dismutase, which converts superoxide anions into hydrogen peroxide as a substrate for subse-

"Corresponding author. quent catalase action. The secondary enzymatic defense includes glutathione reductase and glucose-6-phosphate dehydrogenase. Glutathione reductase reduces glutathione (antioxidant) from its oxidized to its reduced form, and by this recycling, to continue neutralizing more free radicals [5]. Glucose-6-phosphate regenerates NADPH, which creates a reducing environment. These two enzymes support the primary enzymatic defense antioxidants and do not neutralize free radicals directly. The group of non-enzymatic antioxidants contains several subgroups, the main ones being: vitamins (A, E, C), enzyme cofactors (Q10), minerals (zinc and selenium), peptides (glutathione), phenolic acids, and nitrogen compounds (uric acid) [3].

There is great importance in maintaining the fragile balance between these antioxidants and the ROS molecules. For instance, in humans, disturbing this balance can cause serious health problems, such as cancer, cardiovascular and neurodegenerative diseases, and premature aging [6]. 


\section{Synthetic Antioxidants in Pharmaceutical and Food Industries}

Nowadays, most food \& pharmaceutical products contain synthetic antioxidants. These compounds are added to food in order to prolong product shelf life, mainly by preventing the oxidation of unsaturated double bonds of fatty acids. In pharmaceutical products to antioxidants are added to enhance the stability of therapeutic agents that are susceptible to chemical degradation by oxidation. The two most common synthetic antioxidants used today are butylated hydroxyanisole (BHA) and butylated hydroxyltoluene (BHT). Propyl gallate and tert-butylhy-droquinone (TBHQ) are other widely used synthetic antioxidants in the processed-food industry. For example, TBHQ is usually added to food products such as beef and chicken. Though no harmful effect of these synthetic antioxidants has been shown in man, in 2012, the European Food Safety Authority (EFSA) evaluated information regarding several of these antioxidants and established revised acceptable daily intakes of antioxidants for human consumption, setting a proper scale for their use by food companies [7]. Ascorbic acid derivatives, such as ascorbic acid and erythorbic acid; thiol derivatives, such as thioglycerol, cysteine, dithiothreitol, and glutathione; sulfurous-acid salts, such as sodium sulfite, sodium formaldehyde sulfoxylate, and tocopherols, are widely used in the pharmaceutical industry.

Unfortunately, new data indicating that the synthetic antioxidants used in the industry could have carcinogenic effects on human cells resurface every year, thus fueling an intense search for new, natural and efficient antioxidants.

\section{Antioxidants in Plants: Relation to Photosynthesis}

Photosynthesis is an important source of cellular oxidants, and the importance of antioxidants in maintaining high rates of photosynthesis has been shown in many studies [8]. Studies showed that photosynthesis is the source of reactive oxygen species (ROS) and that the photosynthetic electron transport chain operates as a regulatory system for minimizing ROS production in an aerobic environment. In addition, there is a need for a strong and efficient antioxidant network to process ROS effectively and to maintain intracellular ROS pools at low levels [9]. Originally, ROS were recognized as toxic by-products of aerobic metabolism, molecules that have the potential to cause irreversible damage to photosynthetic components and that are removed by antioxidants and antioxidative enzymes. Now, it has become clear that these molecules play an important signaling role in plants, controlling processes such as growth, development, and even programmed cell death [10]. Due to the recent findings, it is of great importance to maintain the fragile balance of the
ROS molecules and antioxidants. Plants usually contain a wide variety of free-radical scavenging molecules, such as phenolic compounds, nitrogen compounds, vitamins, and more [11-14]. Studies have proven that many of these antioxidant compounds exhibit anti-inflammatory, anticarcinogenic, antibacterial, antitumor, or antimutagenic effects in cells [15-19]. Nowadays, the intake of natural antioxidants is associated with reduced risks of cancer, cardiovascular disease, and other diseases.

It has been widely proven that green tea leaves contain a high concentration of polyphenols that act as antioxidants both in vitro and in vivo (in animal and human cells), thus reducing and controlling ROS molecules [20, 21]. Studies conducted on Chinese medical and other medical herbs demonstrated that some herbs, such as rosemary, sage, thyme, and bay, have much stronger antioxidant activity and contain significantly more phenolic acids than common vegetables and fruits, which are considered good natural sources of dietary antioxidants [22, 23].

\section{Antioxidants in Algae}

Due to the widespread use of synthetic antioxidants in food \& pharmaceuticals, scientists are also attempting to develop new and efficient antioxidants from another alternative source found in nature in large amounts-the algae. Algae are widely available aquatic plants containing natural antioxidative compounds, having biological activities that affect the pathogenesis of several diseases, with a relatively low-cost isolation/extraction process [24]. Seaweeds and microalgae make up a big group of photosynthetic marine and freshwater organisms that have adapted to survive in highly complex and competitive environments, including fast temperature changes, different light intensities, nutrient deficiency, $\mathrm{pH}$ changes, and more. The microalgae are the ocean's primary producers, being consumed by other marine organisms for their metabolic energy-requiring processes along the food chain. Recent studies have shown that some species of algae contain large amounts of antioxidants and phenolic compounds. Natural antioxidants found in algae play an important role against various diseases and ageing processes by protecting the cells from oxidative damage $[25,26]$. It has been shown that the red, brown, and green algae, as well as cyanobacteria, display high radical scavenging activities [27-29]. The main antioxidants found in algae are vitamins $\mathrm{C}$ and $\mathrm{E}$ [30], carotenoids $(\beta$ $\& \alpha$-carotene, zeaxanthin, neoxanthin, etc.) [31-34] polyphenols [35], and chlorophylls [36]. In addition, red and brown algae contain high levels of folic acid and folate derivatives [37].

The microalgae are an extremely diverse group of organisms and represent a very important and yet-to-befully-used resource of valuable bioactive compounds and 
biochemicals, such as antioxidants, polysaccharides, pigments, fatty acids, vitamins, and more. For example, $D u$ naliella salina is the most suitable organism for the mass production of $\beta$-carotene as it can produce up to $14 \%$ of its dry weight and can be easily and rapidly cultivated compared to plants [38,39]. As it is well known, $\beta$-carotene is one of the most common food colorants in the world and has been applied to a wide range of food and beverage products, improving their appeal to consumers, besides its antioxidant function. Studies show that algae play an important supporting role in the prevention of or recovery from a variety of diseases, including cancer [40, 41]. Moreover, studies show the great benefits of the cyanobacteria in the prevention of cardiovascular disease, nonalcoholic fatty liver disease, and more. One of the most talked about cyanobacteria that can be used as a dietary supplement is Spirulina. We use two species of these cyanobacteria in order to produce the supplements Spirulina platensis (SP) and Spirulina maxima (SM). Supplementation with these species of Spirulina resulted in lipid-lowering, antioxidant, and anti-inflammatory effects [42-46]. Moreover, its therapeutic benefits were seen in a variety of diseased conditions, such as hypercholesterolemia, cardiovascular diseases, viral infections, and cancer [47]. Furthermore, due to its high nutritional value, Spirulina was recommended by the European Space Agency (ESA) and National Aeronautics and Space Administration (NASA) as one of the primary and important foods during long-term space missions [48]. In addition, in 2011, the Dietary Supplements Information Expert Committee (DSI-EC) of the United States Pharmacopeial Convention awarded Spirulina (SM and SP) the highest possible safety rating and concluded that it is generally safe for consumption. It is noteworthy that the Spirulina species were used in antiquity as a proteinaceous food around Lakes Tchad in Africa and Texcoco in Mexico [49]. With the increasing need to scout for new natural sources of antioxidants, more and more species of algae are now being checked. It was found that industrially cultivated samples of Botryococcus braunii, Neochloris oleoabundans, Isochrysis sp., Chlorella vulgaris, Phaeodactylum tricornutum, Turbinaria ornate, Gayralia oxysperma, Chaetomorpha antennina, Sargassum vulgare, Undaria pinnatifida, Himanthalia elongate, Chondrus crispus, and much more, possess a high antioxidant capacity and could be potential new sources of natural antioxidants [40,50,51].

\section{Screening Methods in Algae}

There are two common methods in use today in the search for antioxidative reactions in algae. The first assay is lipoxygenase-activity determination. There are several methods for assessing this activity. The most commonly used of these methods is based on the fact that hydrop- eroxides generated from the action of the lipoxygenase on linoleic acid with an uptake of oxygen contain a conjugated diene that strongly absorbs UV light at $234 \mathrm{~nm}$. Reaction rates can be determined by measuring product formation through the changes in absorbance. This method can be combined or used separately from the rate of $\mathrm{O}_{2}$ consumption which is followed by an oxygen electrode [52-54]. Another assay is the ferric-reducing ability of plasma (FRAP), which is the most commonly used assay for determination of antioxidant capacity. This is based on the reduction of the ferric to ferrous ion at low $\mathrm{pH}$, which causes a colored ferrous-tripyridyltriazine complex to form. Comparing the absorbance changes at 590 $593 \mathrm{~nm}$ of the reaction mixtures to that of known concentrations of mixtures (usually ascorbate or $\alpha$-tocopherol) containing ferrous ions, gives us the FRAP value of our test mixture. This assay gives fast and reliable results whether with a single or a mixture of antioxidants in various solutions. The reaction is linearly related to the molar concentration of the antioxidant [55]. An example of antioxidant activity in microalgae, using FRAP method, are presented in Figures $\mathbf{1}$ and $\mathbf{2}$.

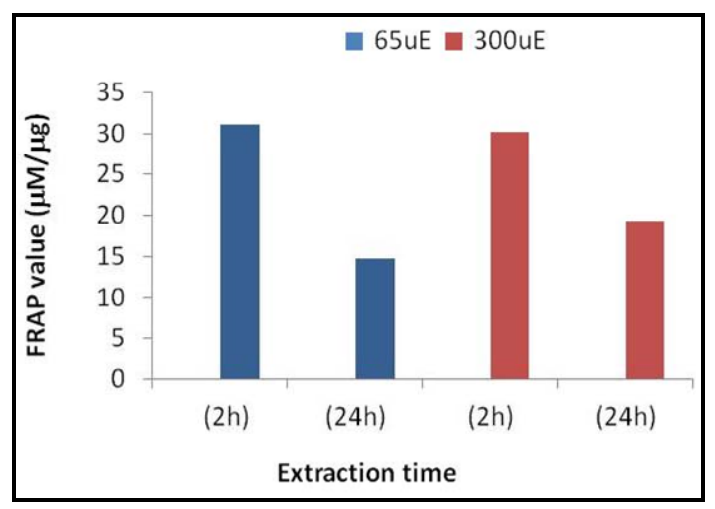

Figure 1. Total antioxidant activity presented as total mean FRAP value in $\mu \mathrm{M}$ per $\mu \mathrm{g}$ crude extract of dry Ankyra sp. The algae were grown under different light intensities, i.e., 65 and $300 \mu$ mole quanta $\mathrm{m}^{-2} \cdot \mathrm{s}^{-1}(\mathrm{uE})$.

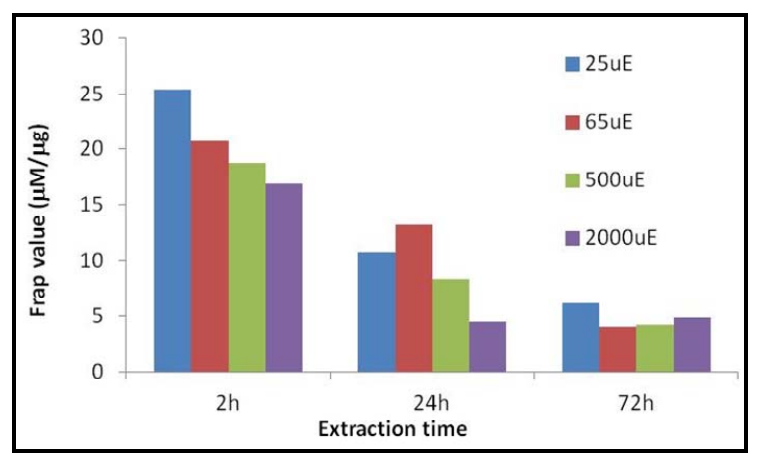

Figure 2. Total antioxidant activity presented as mean total FRAP value in $\mu \mathrm{M}$ per $\mu \mathrm{g}$ crude extract of dry Dunaliella salina. The algae were grown under various light intensities $25,65,500$ and $2000 \mu$ mole quanta $\mathrm{m}^{-2} \cdot \mathrm{s}^{-1}(\mathrm{uE})$. 


\section{Antioxidants in Food}

Regular consumption of vegetables and fruits has been recognized as reducing the risk of chronic diseases [56]. Studies demonstrate that an antioxidant-rich diet has a very positive health impact in the long run $[57,58]$. It is a well-known fact that citrus fruits (oranges, lemons, etc.) contain a high amount of natural antioxidants, such as vitamin C. Blueberries, strawberries, grapes, plums, prunes, red beans, spinach, kale, broccoli flowers, alfalfa sprouts, and more have been proven to contain a high amount of antioxidants and have been incorporated into many dietary menus [59,60]. Furthermore, there are some new and unique antioxidants that have been discovered in spinach. $\mathrm{NAO}$ is an aqueous spinach-leaf extract that contains derivatives of flavonoids and $p$-coumaric acid. The biological activity of NAO has been shown to be beneficial in preventing prostate cancer. Moreover, glucosylated flavonoids that were found in that extract exhibit anti-inflammatory activities [61]. Recent studies also suggested that fruit-like jackfruit, araticu-domato, pindo palm, and mandacaru-de-trêsquinas are good sources of vitamins $\mathrm{C}$ and $A$ and phenolic compounds [62,63]. In addition, there are studies that research genetic, chemical, or biological modification in order to increase the antioxidant potency of fruits [64].

\section{Supplements}

The most common antioxidants given as food supplements are vitamins $\mathrm{C}$ (aka ascorbic acid and ascorbate) and $\mathrm{E}$. Vitamin $\mathrm{C}$ is a cofactor in enzymatic reactions, including several collagen syntheses and an electron donor, which makes it a potent water-soluble antioxidant in humans. If these reactions are disrupted or damaged, they can cause severe health problems, such as scurvy [65]. Furthermore, studies showed that some gene expression and protein assimilation functions are dependent on dietary vitamin C [66]. Vitamin E is a fat-soluble antioxidant whose function is to stop the production of ROS formed due to fat oxidation. Among other functions, it is involved in cell signaling, gene expression regulation, immune function, and other metabolic processes [67]. Current medical supplements of vitamin E usually provide only synthetically produced $\alpha$-tocopherol, whereas natural supplements provide mixed tocopherols and contain the eight isomeric forms of $\alpha$-tocopherol. Both vitamins are produced today both synthetically and from natural sources. It is said that the naturally produced vitamins have a much higher percentage of absorbance in the human body. The regular intake of these vitamins is associated with a reduced risk of chronic diseases, such as cancer, cardiovascular disease, and cataracts, through their antioxidant mechanisms. The antioxidant supplement market has been increasing rapidly for the past several years. The global vitamin and supplement market is worth close to $\$ 68$ billion, with the US being the world leader in terms of market share for vitamins and supplements with around $30 \%$ of the world market. In 2010, vitamin E imported by the EU reached up to $\$ 421$ million and vitamin C-\$361 million. In addition, according to Business Insights, the vitamin and mineral market in the US will see compound annual growth of $4.5 \%$, nearing $\$ 30$ billion, in 2015 [68].

\section{Summary}

As already said, the main goal of researchers today is to find natural antioxidants that will replace the synthetic ones in the food, pharmaceutical, and cosmetic industries [69]. Though it has not been proven that synthetic antioxidants are harmful to human cells, the EFSA has been carefully monitoring their amounts, preventing food companies from exaggerating in their dosages. Seaweeds and microalgae are a common, available, and valuable potential source of natural antioxidants. They have a very high concentrated nutritional value, containing a variety of vitamins and other non-enzymatic antioxidants, and are relatively inexpensive to mass-produce and extract. Furthermore, several studies have shown the multiple benefits of some algal species in preventing chronic and even lethal diseases. It is more imminent than ever that algae might become the main future source of natural antioxidants (Figure 3).

\section{Acknowledgements}

The authors thank Dr. Alla Alster, Dr. Dovi Kelman, Moran Topf, Barak Vasker, Dr. Miriam Zigman and Said Abu Ghosh for their contribution with cultures of algae and help with the experiments. This research was supported by grants awarded by the Israel Ministry of Energy and Water Resources, the Israel Ministry of Science

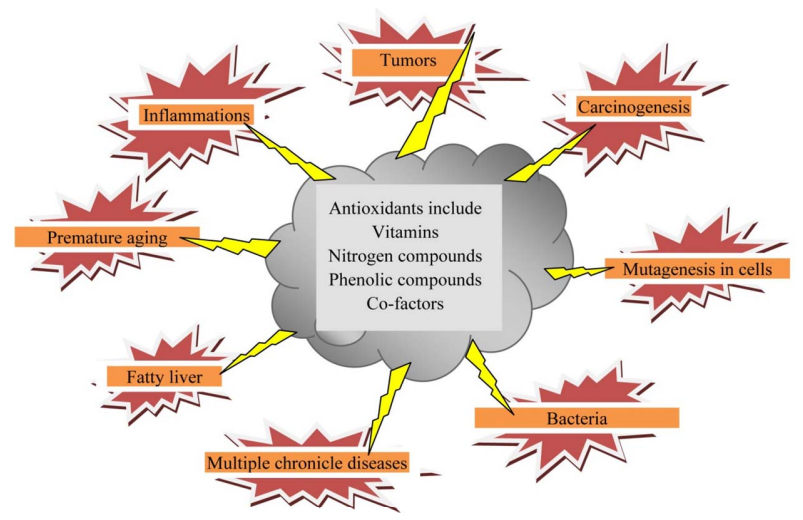

Figure 3. Summary of antioxidant activities preventing common-disease conditions. 
and Technology, the "Varda Rabin” Foundation, NATO sfp 981,883.

\section{REFERENCES}

[1] B. Halliwell and J. M. C. Gutteridge, "The Definition and Measurement of Antioxidants in Biological Systems," Free Radical Biology and Medicine, Vol. 18, No. 1, 1995, pp. 125-126. doi:10.1016/0891-5849(95)91457-3

[2] B. Halliwell, "Biochemistry of Oxidative Stress," Biochemical Society Transactions, Vol. 35, No. 5, 2007, pp. 1147-1150. doi:10.1042/BST0351147

[3] M. Carocho and I. C. F. R. Ferreira, “A Review on Antioxidants, Prooxidants and Related Controversy: Natural and synthetic compounds. Screening and Analysis Methodologies and Future Perspectives," Food and Chemical Toxicology, Vol. 51, 2013, pp. 15-25.

doi:10.1016/j.fct.2012.09.021

[4] K. Rahman, "Studies on Free Radicals, Antioxidants, and Co-Factors," Clinical Interventions in Aging, Vol. 2, No. 2, 2007, pp. 219-236.

[5] D. V. Ratnam, D. D. Ankola, V. Bhardwaj, D. K. Sahana and M. N. V. R. Kumar, "Role of Antioxidants in Prophylaxis and Therapy: A Pharmaceutical Perspective,” Journal of Controlled Release, Vol. 113, No. 3, 2006, pp. 189207. doi:10.1016/j.jconrel.2006.04.015

[6] M. Valko, D. Leibfritz, J. Moncol, M. T. D. Cronin, M. Mazur and J. Telser, "Free Radicals and Antioxidants in Normal Physiological Functions and Human Disease," International Journal of Biochemistry \& Cell Biology, Vol. 39, No. 1, 2007, pp. 44-84. doi:10.1016/j.biocel.2006.07.001

[7] EFSA, "Scientific Opinion on the Reevaluation of Butylated Hydroxytoluene BHT (E 321) as a Food Additive. EFSA Panel on Food Additives and Nutrient Sources Added to Food (ANS)," European Food Safety Authority Journal, Vol. 10, No. 3, 2012, p. 2588.

http://www.efsa.europa.eu/en/efsajournal/doc/2588.pdf

[8] C. H. Foyer and G. Noctor, "Redox Sensing and Signalling Associated with Reactive Oxygen in Chloroplasts, Peroxisomes and Mitochondria,” Physiologia Plantarum, Vol. 119, No. 3, 2003, pp. 355-364. doi:10.1034/j.1399-3054.2003.00223.x

[9] C. H. Foyer and S. Shigeoka, "Understanding Oxidative Stress and Antioxidant Functions to Enhance Photosynthesis," Plant Physiology, Vol. 155, No. 1, 2011, pp. 93100. doi:10.1104/pp.110.166181

[10] J. Bailey-Serres and R. Mittler, "The Roles of Reactive Oxygen Species in Plant Cells (Editorial)," Plant Physiology, Vol. 141, No. 2, 2006, p. 311doi:10.1104/pp.104.900191.

[11] G. Agati, E. Azzarello, S. Pollastri and M. Tattini, "Flavonoids as Antioxidants in Plants: Location and Functional Significance,” Plant Science, Vol. 196, 2012, pp. 67-76. doi:10.1016/j.plantsci.2012.07.014

[12] C. J. Chiang, H. Kadouh and K. Q. Zhou, "Phenolic Compounds and Antioxidant Properties of Gooseberry as Affected by in Vitro Digestion," LWT-Food Science and Te- chnology, Vol. 51, No. 2, 2013, pp. 417-422. doi:10.1016/j.lwt.2012.11.014

[13] C. C. Wong, H. B. Li, K. W. Cheng and F. Chen, “A Systematic Survey of Antioxidant Activity of 30 Chinese Medicinal Plants Using the Ferric Reducing Antioxidant Power Assay,” Food Chemistry, Vol. 97, No. 4, 2006, pp. 705-711. doi:10.1016/j.foodchem.2005.05.049

[14] Y. Z. Cai, M. Sun and H. Corke, "Antioxidant Activity of Betalains from Plants of the Amaranthaceae,” Journal of Agricultural and Food Chemistry, Vol. 51, No. 8, 2003, pp. 2288-2294. doi:10.1021/jf030045u

[15] B. Halliwell, "Free Radicals, Antioxidants, and Human Disease-Curiosity, Cause, or Consequence,” Lancet, Vol. 344, No. 8924, 1994, pp. 721-724. doi:10.1016/S0140-6736(94)92211-X

[16] R. W. Owen, A. Giacosa, W. E. Hull, R. Haubner, B. Spiegelhalder and H. Bartsch, "The Antioxidant/Anticancer Potential of Phenolic Compounds Isolated from Olive Oil," European Journal of Cancer, Vol. 36, No. 10, 2000, pp. 1235-1247. doi:10.1016/S0959-8049(00)00103-9

[17] Y. Z. Cai, Q. Luo, M. Sun and H. Corke, “Antioxidant Activity and Phenolic Compounds of 112 Traditional Chinese Medicinal Plants Associated with Anticancer," Life Sciences, Vol. 74, No. 17, 2004, pp. 2157-2184. doi:10.1016/j.lfs.2003.09.047

[18] J. H. Xiong, S. C. Li, W. J. Wang, Y. P. Hong, K. J. Tang and Q. S. Luo, "Screening and Identification of the Antibacterial Bioactive Compounds from Lonicera japonica Thunb. Leaves," Food Chemistry, Vol. 138, No. 1, 2013, pp. 327-333. doi:10.1016/j.foodchem.2012.10.127

[19] G. A. El-Chaghaby, A. F. Ahmad and E. S. Ramis, "Evaluation of the Antioxidant and Antibacterial Properties of Various Solvents Extracts of Annona squamosa L. Leaves,” Arabian Journal of Chemistry, 2011, in press. doi:10.1016/j.arabjc.2011.06.019

[20] B. Frei and J. V. Higdon, "Antioxidant Activity of Tea Polyphenols in Vivo: Evidence from Animal Studies,” Journal of Nutrition, Vol. 133, No. 1, 2003, pp. 3275s-3284s.

[21] J. V. Higdon and B. Frei, "Tea Catechins and Polyphenols: Health Effects, Metabolism, and Antioxidant Functions," Critical Reviews in Food Science and Nutrition, Vol. 43, No. 1, 2003, pp. 89-143. doi:10.1080/10408690390826464

[22] B. Bozin, N. Mimica-Dukic, N. Simin and G. Anackov, "Characterization of the Volatile Composition of Essential Oils of Some Lamiaceae Spices and the Antimicrobial and Antioxidant Activities of the Entire Oils,” Journal of Agricultural and Food Chemistry, Vol. 54, No. 5, 2006, pp. 1822-1828. doi:10.1021/jf051922u

[23] V. Katalinic, M. Milos, T. Kulisic and M. Jukic, "Screening of 70 Medicinal Plant Extracts for Antioxidant Capacity and Total Phenols," Food Chemistry, Vol. 94, No. 4, 2006, pp. 550-557. doi:10.1016/j.foodchem.2004.12.004

[24] S. Lordan, R. P. Ross and C. Stanton, "Marine Bioactives as Functional Food Ingredients: Potential to Reduce the Incidence of Chronic Diseases," Marine Drugs, Vol. 9, No. 6, 2011, pp. 1056-1100. doi:10.3390/md9061056

[25] R. Karawita, M. Senevirathne, Y. Athukorala, A. Affan, 
Y.-J. Lee, S.-K. Kim, et al., "Protective Effect of Enzymatic Extracts from Microalgae against DNA Damage Induced by $\mathrm{H}_{2} \mathrm{O}_{2}$," Marine Biotechnology, Vol. 9, No. 4, 2007, pp. 479-490. doi:10.1007/s10126-007-9007-3

[26] K. N. Kim, S. J. Heo, C. B. Song, J. Lee, M. S. Heo, I. K. Yeo, et al., "Protective Effect of Ecklonia cava Enzymatic Extracts on Hydrogen Peroxide-Induced Cell Damage," Process Biochemistry, Vol. 41, No. 12, 2006, pp. 23932401. doi:10.1016/j.procbio.2006.06.028

[27] Y. X. Li, Y. Li, S. H. Lee, Z. J. Qian and S. K. Kim, "Inhibitors of Oxidation and Matrix Metalloproteinases, Floridoside, and D-Isofloridoside from Marine Red Alga Laurencia undulata," Journal of Agricultural and Food Chemistry, Vol. 58, No. 1, 2010, pp. 578-586. doi:10.1021/jf902811j

[28] K. Li, X. M. Li, N. Y. Ji and B. G. Wang, "Natural Bromophenols from the Marine Red Alga Polysiphonia Urceolata (Rhodomelaceae): Structural Elucidation and DPPH Radical-Scavenging Activity,” Bioorganic and Medicinal Chemistry, Vol. 15, No. 21, 2007, pp. 6627-6631. doi:10.1016/j.bmc.2007.08.023

[29] S. Singh, B. N. Kate and U. C. Banerjee, "Bioactive Compounds from Cyanobacteria and Microalgae: An Overview," Critical Reviews in Biotechnology, Vol. 25, No. 3, 2005, pp. 73-95. doi:10.1080/07388550500248498

[30] P. MacArtain, C. I. R. Gill, M. Brooks, R. Campbell and I. R. Rowland, "Nutritional Value of Edible Seaweeds," $\mathrm{Nu}$ trition Reviews, Vol. 65, No. 12, 2007, pp. 535-543. doi:10.1111/j.1753-4887.2007.tb00278.X

[31] C. C. Hu, J. T. Lin, F. J. Lu, F. P. Chou and D. J. Yang, “Determination of Carotenoids in Dunaliella salina Cultivated in Taiwan and Antioxidant Capacity of the Algal Carotenoid Extract," Food Chemistry, Vol. 109, No. 2, 2008, pp. 439-446. doi:10.1016/j.foodchem.2007.12.043

[32] J. A. Haugan and S. Liaaenjensen, “Algal Carotenoids. 54. Carotenoids of Brown Algae (Phaeophyceae),” Biochemical Systematics and Ecology, Vol. 22, No. 1, 1994, pp. 31-41. doi:10.1016/0305-1978(94)90112-0

[33] E. Christaki, E. Bonos, I. Giannenas and P. Florou-Paneri, "Functional Properties of Carotenoids Originating from Algae," Journal of the Science of Food and Agriculture, Vol. 93, No. 1, 2013, pp. 5-11. doi:10.1002/jsfa.5902

[34] K. H. Cha, H. J. Lee, S. Y. Koo, D. G. Song, D. U. Lee and C. H. Pan, "Optimization of Pressurized Liquid Extraction of Carotenoids and Chlorophylls from Chlorella vulgaris," Journal of Agricultural and Food Chemistry, Vol. 58, No. 2, 2010, pp. 793-797. doi:10.1021/jf902628j

[35] A. Bocanegra, S. Bastida, J. Benedí, S. Ródenas and F. J. Sánchez-Muniz, "Characteristics and Nutritional and Cardiovascular-Health Properties of Seaweeds," Journal of Medicinal Food, Vol. 12, No. 2, 2009, pp. 236-258. doi:10.1089/jmf.2008.0151

[36] K. H. Cha, S. W. Kang, C. Y. Kim, B. H. Um, Y. R. Na and C. H. Pan, "Effect of Pressurized Liquids on Extraction of Antioxidants from Chlorella vulgaris," Journal of Agricultural and Food Chemistry, Vol. 58, No. 8, 2010, pp. 4756-4761. doi:10.1021/jf100062m

[37] A. R. B. de Quirós, C. C. de Ron, J. López-Hernández and M. A. Lage-Yusty, "Determination of Folates in Sea- weeds by High-Performance Liquid Chromatography," Journal of Chromatography A, Vol. 1032, No. 1-2, 2004, pp. 135-139. doi:10.1016/j.chroma.2003.11.027

[38] F. B. Metting, "Biodiversity and Application of Microalgae,” Journal of Industrial Microbiology \& Biotechnology, Vol. 17, No. 5-6, 1996, pp. 477-489. doi:10.1007/BF01574779

[39] K. Miyashita, "Function of Marine Carotenoids," Food Factors for Health Promotion, Vol. 61, 2009, pp. 136146. doi:10.1159/000212746

[40] D. Kelman, E. K. Posner, K. J. McDermid, N. K. Tabandera, P. R. Wright and A. D. Wright, "Antioxidant Activity of Hawaiian Marine Algae,” Marine Drugs, Vol. 10, No. 2, 2012, pp. 403-416. doi:10.3390/md10020403

[41] C. S. Ku, Y. Yang, Y. Park and J. Lee, "Health Benefits of Blue-Green Algae: Prevention of Cardiovascular Disease and Nonalcoholic Fatty Liver Disease," Journal of Medicinal Food, Vol. 16, No. 2, 2013, pp. 103-111. doi:10.1089/jmf.2012.2468

[42] P. Parikh, U. Mani and U. Iyer, "Role of Spirulina in the Control of Glycemia and Lipidemia in Type 2 Diabetes Mellitus,” Journal of Medicinal Food, Vol. 4, No. 4, 2001, pp. 193-199. doi:10.1089/10966200152744463

[43] K. Iwata, T. Inayama and T. Kato, "Effects of Spirulina platensis on Plasma Lipoprotein Lipase Activity in Fructose-Induced Hyperlipidemic Rats," Journal of Nutritional Science and Vitaminology, Vol. 36, No. 2, 1990, pp. 165-171. doi:10.3177/jnsv.36.165

[44] A. Ramamoorthy and S. Premakumari, "Effect of supplementation of Spirulina on Hypercholesterolemic Patients," Journal of Food Science and Technology-Mysore, Vol. 33, No. 2, 1996, pp. 124-127.

[45] U. V. Mani, S. Desai and U. Iyer, "Studies on the LongTerm Effect of Spirulina Supplementation on Serum Lipid Profile and Glycated Proteins in NIDDM Patients," Journal of Neutraceuticals Functional and Medical Foods, Vol. 2, No. 3, 2000, pp. 25-32. doi:10.1300/J133v02n03_03

[46] H. J. Park, Y. J. Lee, H. K. Ryu, M. H. Kim, H. W. Chung and W. Y. Kim, "A Randomized Double-Blind, Placebo-Controlled Study to Establish the Effects of Spirulina in Elderly Koreans," Annals of Nutrition and Metabolism, Vol. 52, No. 4, 2008, pp. 322-328. doi:10.1159/000151486

[47] R. T. Deng and T. J. Chow, "Hypolipidemic, Antioxidant, and Antiinflammatory Activities of Microalgae Spirulina," Cardiovascular Therapeutics, Vol. 28, No. 4, 2010, pp. e33-e45. doi:10.1111/j.1755-5922.2010.00200.x

[48] R. J. Marles, M. L. Barrett, J. Barnes, M. L. Chavez, P. Gardiner, R. Ko, et al., "United States Pharmacopeia Safety Evaluation of Spirulina," Critical Reviews in Food Science and Nutrition, Vol. 51, No. 7, 2011, pp. 593-604. doi:10.1080/10408391003721719.

[49] M. Sánchez, J. Bernal-Castillo, C. Rozo and I. Rodríguez, "Spirulina (Arthrospira): An Edible Microorganism: A Review," Universitas Scientiarum, Revista de la Facultad de Ciencias, Pontificia Universidad Javeriana, Vol. 8, No. 1, 2003, pp. 7-24.

http://www.algbiotek.com/bilimsel/PDF\%20Dosyalar/spi 
rulina(arthrospira)genelozelliklerivebesinselonemi.pdf

[50] K. Goiris, K. Muylaert, I. Fraeye, I. Foubert, J. De Brabanter and L. De Cooman, "Antioxidant Potential of Microalgae in Relation to Their Phenolic and Carotenoid Content,” Journal of Applied Phycology, Vol. 24, No. 6, 2012, pp. 1477-1486. doi:10.1007/s10811-012-9804-6

[51] M. Plaza, A. Cifuentes and E. Ibánez, "In the Search of New Functional Food Ingredients from Algae,” Trends in Food Science and Technology, Vol. 19, No. 1, 2008, pp. 31-39. doi:10.1016/j.tifs.2007.07.012

[52] B. Axelrod, T. M. Cheesebrough and S. Laakso, "Lipoxygenase from Soybeans," Methods in Enzymology, Vol. 71, 1981, pp. 441-451. doi:10.1016/0076-6879(81)71055-3

[53] G. E. Anthon and D. M. Barrett, "Colorimetric Method for the Determination of Lipoxygenase Activity,” Journal of Agricultural and Food Chemistry, Vol. 49, No. 1, 2001, pp. 32-37. doi:10.1021/jf000871s

[54] R. Matsukawa, Z. Dubinsky, K. Masaki, T. Takeuchi and I. Karube, "Enzymatic Screening of Microalgae as a Potential Source of Natural Antioxidants," Applied Biochemistry and Biotechnology, Vol. 66, No. 3, 1997, pp. 239-247. doi:10.1007/BF02785590

[55] I. F. F. Benzie and J. J. Strain, "The Ferric Reducing Ability of Plasma (FRAP) as a Measure of 'Antioxidant Power': The FRAP Assay,” Analytical Biochemistry, Vol. 239, No. 1, 1996, pp. 70-76. doi:10.1006/abio.1996.0292

[56] A. Dembinska-Kiec, O. Mykkanen, B. Kiec-Wilk and H. Mykkanene, "Antioxidant Phytochemicals against Type 2 Diabetes,” British Journal of Nutrition, Vol. 99, No. ES1, 2008, pp. ES109-ES117.

[57] H. P. Y. Sin, D. T. L. Liu and D. S. C. Lam, "Lifestyle Modification, Nutritional and Vitamins Supplements for Age-Related Macular Degeneration,” Acta Ophthalmologica, Vol. 91, No. 1, 2013, pp. 6-11. doi:10.1111/j.1755-3768.2011.02357.x

[58] L. M. Willis, B. Shukitt-Hale and J. A. Joseph, "Recent Advances in Berry Supplementation and Age-Related Cognitive Decline," Current Opinion in Clinical Nutrition and Metabolic Care, Vol. 12, No. 1, 2009, pp. 91-94. doi:10.1097/MCO.0b013e32831b9c6e

[59] G. H. Cao, R. M. Russell, N. Lischner and R. L. Prior, "Serum Antioxidant Capacity is Increased by Consumption of Strawberries, Spinach, Red Wine or Vitamin C in Elderly Women,” Journal of Nutrition, Vol. 128, No. 12, 1998, pp. 2383-2390.

[60] S. Grossman, R. Reznik, T. Tamari and M. Albeck, "New
Plant Water Soluble Antioxidant (NAO) from Spinach,” In: K. Asada and T. Toshikawa, Eds., Frontiers of Reactive Oxygen Species in Biology and Medicine, Elsevier Science, Amsterdam, 1994, pp. 57-73.

[61] S. Grossman, S. Dovrat and M. Bergman, "Natural Antioxidants: Just Free Radical Scavengers or Much More?” Trends in Cancer Research, Vol. 7, 2011, pp. 57-73.

[62] S. B. Swami, N. J. Thakor, P. M. Haldankar and S. B. Kalse, "Jackfruit and Its Many Functional Components as Related to Human Health: A Review," Comprehensive Reviews in Food Science and Food Safety, Vol. 11, No. 6, 2012, pp. 565-576. doi:10.1111/j.1541-4337.2012.00210.x

[63] M. C. Pereira, R. S. Steffens, A. Jablonski, P. F. Hertz, A. D. Rios, M. Vizzotto, et al., "Characterization, Bioactive Compounds and Antioxidant Potential of Three Brazilian Fruits," Journal of Food Composition and Analysis, Vol. 29, No. 1, 2013, pp. 19-24. doi:10.1016/j.jfca.2012.07.013

[64] F. S. Gomes, P. A. Costa, M. B. D. Campos, R. V. Tonon, S. Couri and L. M. C. Cabral, "Watermelon Juice Pretreatment with Microfiltration Process for Obtaining Lycopene," International Journal of Food Science and Technology, Vol. 48, No. 3, 2013, pp. 601-608. doi:10.1111/ijfs.12005

[65] S. J. Padayatty, A. Katz, Y. H. Wang, P. Eck, O. Kwon, J. H. Lee, et al., "Vitamin C as an Antioxidant: Evaluation of Its Role in Disease Prevention," Journal of the American College of Nutrition, Vol. 22, No. 1, 2003, pp. 18-35.

[66] M. Lucock, Z. Yates, L. Boyd, C. Naylor, J. H. Choi, X. $\mathrm{Ng}$, et al., "Vitamin C-Related Nutrient-Nutrient and Nutrient-Gene Interactions that Modify Folate Status,” European Journal of Nutrition, Vol. 52, No. 2, 2013, pp. 569582. doi:10.1007/s00394-012-0359-8

[67] S. Salinthone, A. R. Kerns, V. Tsang and D. W. Carr, "Alpha-Tocopherol (Vitamin E) Stimulates Cyclic AMP Production in Human Peripheral Mononuclear Cells and Alters Immune Function," Molecular Immunology, Vol. 53, No. 3, 2013, pp. 173-178. doi:10.1016/j.molimm.2012.08.005

[68] Industry Reports. http://www.reportlinker.com/ci02037/Vitamin-and-Suppl ement.html

[69] I. Binic, V. Lazarevic, M. Ljubenovic, J. Mojsa and D. Sokolovic, "Skin Ageing: Natural Weapons and Strategies," Evidence-Based Complementary and Alternative Medicine, Vol. 2013, No. 2013, 2013, Article ID: 827248. doi:10.1155/2013/827248 